\title{
Las cubiertas de los libros como mecanismo de marketing editorial
}

Book covers as a marketing editorial tool

\section{Juan Miguel SÁnchez VigIL (1), Juan Carlos Marcos Recio (2) y Ricardo Villegas Tovar (3)}

Biblioteconomía y Documentación, Adv. Ciudad Universitaria, S/N, Universidad Complutense, jmsvigil@telefonica.net, (2) jmarcos@ccinf.ucm.es, (3) Biblioteca "Niels Bohr”, Ciudad Universitaria, Benemérita Universidad Autónoma de Puebla, Puebla, México, ricardo.villegas@dgb.buap.mx

\begin{abstract}
Resumen
La industrial editorial española ocupa un lugar destacado en la edición, diseño, impresión y comercialización de libros y revistas dentro del panorama mundial. En Europa, sólo Inglaterra y Alemania superan el proceso productivo de España. En Latinoamérica, nuestro mercado natural, las ventas de libros suponen una parte importante de nuestras exportaciones, incluido Brasil y Estados Unidos. Pero, hacer un libro, a pesar de ser una industria milenaria, no resulta fácil, ahora que la tecnología desplaza el papel como elemento de comunicación. En el proceso de creación, el diseño se ha convertido en un elemento indispensable. La cubierta ayuda a vender un libro y es un elemento fundamental del marketing. Por este motivo, las editoriales apuestan por ilustradores e ilustraciones de calidad para hacer más atractiva la venta. Se propone un análisis de este aspecto del mundo editorial español, a través de las principales editoriales.
\end{abstract}

Palabras clave: Editoriales. Marketing. Cubiertas. Ilustraciones. Libros.

\section{Introducción}

La industria editorial española goza de buena salud. Desde hace más de una década se encuentra entre las tres o cuatro principales del mundo, gracias sobre todo a un mercado en alza como es Latinoamérica, donde España es el referente editorial, aunque otros países están avanzando considerablemente. Esta situación de privilegio no es fruto de la casualidad, sino del esfuerzo de una serie de editores que han creído en el libro como elemento de cultura, enseñanza, entretenimiento, comunicación etc.

España cuenta con una tradición editorial importante. Algunas consiguieron sobrevivir a agitados siglos donde la lectura era para unos pocos y donde comprar un libro estaba al alcance de menos. Luego, con el tiempo, entrados en la ilustración, los movimientos políticos generaron una importante lectura de periódicos y conse-

\begin{abstract}
The Spanish publishing industry occupies a noteworthy position in the editing, designing, printing and marketing of books and magazines throughout the world. In Europe, only England and Germany surpass Spain's level of production. In Latin America, which is a natural market, book sales represent an important part of the exports, including to Brazil and the United States. However, it is not easy to publish a book nowadays, despite the fact that book publication dates back for well over 1,500 years, because modern technology has displaced paper as a major means for communication. In the creative process, Design has become an indispensable element. The book cover helps to sell a book and it is a fundamental marketing tool. For this reason, publishing companies rely heavily on quality illustrators and illustrations in order to enhance the appeal of the book. This aspect of the Spanish publishing world is analyzed through a study of the leading publishing companies.
\end{abstract}

Keywords: Publishing companies. Marketing. Covers. Illustrations. Books.

cuentemente de libros. En la calle los movimientos convulsos de la política de entonces, los escritores románticos del siglo XIX y los incipientes científicos que había en este país, abrieron las puertas a un mundo editorial que no tenía claros su horizonte. Llegó el siglo XX y con él, la aparición de algunas editoriales que se convertirían luego en el sustento actual de la industria española, considerada entre las más importantes del mundo.

Aunque el producto final: libro, folleto, folletín, cuento, novela, etc., parece sencillo, la práctica indica que es algo más complicado; sobre todo la última fase, es decir, el marketing y la venta. Podría decirse que un buen libro es aquel que los lectores deciden comprar y/o leer. Pero cómo se sabe con antelación que un tema interesa o no a los lectores. Hay cientos de ejemplos de libros que fueron rechazados por varias editoriales y que luego se convirtieron en los más 
vendidos y aceptados por parte del público. A Carlos Ruiz Zafón y "La sombra del viento" le sucedió algo parecido. En el otro extremo, hay situaciones en los que las editoriales tienen suficientes garantías de que un libro o un autor serán superventas. En medio, aciertos y errores en los que las editoriales suman ingresos o pierden porque las ventas no han alcanzado las previsiones.

Un libro no es sólo el contenido. Quizás, sea lo más importante, pero sin una buena portada, sin una campaña de marketing, sin un esfuerzo publicitario, sin apoyos de la editorial, sin presentaciones, sin firmas en las ferias editoriales... no alcanzaría los mismos objetivos. Se propone por tanto, analizar el panorama actual de la industria editorial española, ver el valor de las portadas de algunos libros y conocer cómo afectan los derechos de autor sobre el diseño de la portada. Grandes y pequeños ilustrados trabajaron para dar vida a las portadas y este es un pequeño homenaje.

\section{La industria editorial hoy en España}

El mundo de los libros supone una atracción física que ha acompañado al ser humano desde hace siglos. Tan sólo las generaciones actuales que nacieron con los libros virtuales no detectan esa sensación. Poseer un libro no es sólo guardar y atesorar el conocimiento, es tener en las manos de cada uno el saber, el entendimiento, la comprensión de un mundo en el que vive. Los libros han sido el fiel reflejo de una sociedad y el mejor amigo de la soledad. Su creación, su lectura, su conservación y su entrega generosa a otras generaciones es el ejemplo más significativo del ser humano. La cultura servida para que mejore la sociedad.

Ese proceso se lleva a cabo cuando el libro deja de ser un objeto de unos pocos y se convierte en valor de muchos. Cuando la sociedad entiende en el siglo XX que la educación ah de llegar a todo el mundo, la industria editorial se plantea cubrir esas necesidades que se detectan en la sociedad. Pero el proceso ha sido lento. Si se pregunta a la generación de los cincuenta/sesenta del siglo pasado sobre lo que son los libros, encontraríamos respuestas diversas, pero una similar: los libros de estudios eran compartidos y uno sólo recogía todas las materias (enciclopedia). A partir de la época del bienestar en España, precisamente cuando aparecen las que hoy son grandes editoriales, las siguientes generaciones estudiaron cada curso con un libro de texto diferente.

No este un estudio exhaustivo de la industria editorial, pero para establecer la importancia que tiene la cubierta en el proceso de creación y venta del libro, antes se ha de conocer la situación actual de la industria editorial y el idioma español, en el que publican la mayoría de las editoriales españolas. En este sentido, los libros son referente individual, ya que cada persona es libre de comprar y usarlos de forma colectiva, a través de las bibliotecas. Desde luego, la primera consideración importante es el idioma. Baste como ejemplo una información publicada por el Instituto de Comercio Exterior de España (ICEX), de un estudio patrocinado por la Asociación de Bibliotecas norteamericanas (ALA), en el que se indica que un $78 \%$ de las bibliotecas públicas de EE.UU. afirma que han desarrollado programas y servicios en español para atender la creciente demanda en este idioma, el primero, después del inglés, más solicitado entre sus usuarios. El estudio titulado "Atendiendo a los hablantes de otro idioma no inglés en las bibliotecas públicas de USA 2007" destaca que casi 21 millones de personas en EE.UU. habla poco o casi nada de inglés, un $50 \%$ más que hace diez años. En este sentido las bibliotecas están aumentando sus esfuerzos para atender a esta población que comprende no solamente hispanohablantes sino otras comunidades con lenguas de origen asiático e indoeuropeo.

Pero ¿Cuál es la realidad del sector editorial español? ¿Cuáles son sus estrategias? ¿Hacia dónde camina? ¿Qué tipo de medidas están utilizando para entrar en otros países que no emplean en español? No hay respuestas exactas, pero sí algunas aproximaciones a lo que se está haciendo y las perspectivas de mejora.

Como punto de partida se ha de considerar válido el informe anual que publica la Federación de Gremio de Editores de España (FGEE) sobre el Sector Editorial Español, en el que se toma como referencia los datos de editoriales privadas asociadas a esta Federación. El último publicado es de 2006. Las cifras macroeconómicas del estudio de COMERCIO INTERIOR se centran en los siguientes apartados: $776 \mathrm{em}-$ presas editoriales y agremiadas, 68.930 títulos editados (incluidas las reimpresiones), 338,09 millones de ejemplares publicados, 4.905 ejemplares de tirada media, 346.706 títulos vivos en oferta, 228,22 millones de ejemplares vendidos, y 3.014,54 millones de euros de facturación en el mercado interior.

En este informe se indica que la producción editorial ha aumentado ya que en el 2006, el volumen total de ejemplares publicados fue de 338.090 .000 , es decir, un $5,2 \%$ más que en 2005. En cuanto al número total de títulos, el ejercicio se saldó con 68.930 , de los que un $51,3 \%$ son novedades o primeras ediciones y el 
$48,7 \%$ son reediciones o reimpresiones. Además, los datos de facturación también fueron positivos, ya que alcanzaron los 3.014 millones de euros, es decir, un $2,8 \%$ más que en 2005, creciendo por encima de la inflación. En ventas es donde se produjo un paso atrás, ya que se vendieron 228.200 .000 , lo que supone un $1 \%$ menos que en 2005 .

Por último, se debe tener en cuenta los datos de la parte lectora referidos al mismo periodo y publicados en el mismo informe, en el que además de la Federación de Gremios de Editores de España colabora la Dirección General del Libro, Archivos y Bibliotecas. En 2006, el porcentaje de población lectora alcanzó el 55,5\%, lo que supone una tasa ligeramente superior a la media de los tres últimos años que se quedó en un $55,0 \%$.

Conviene precisar que este tipo de informes tienen en cuenta el perfil del lector, lectores según sexo y edad, motivos de la lectura, materias más leídas e idioma de la lectura, pero no se constatan datos sobre la importancia que puede tener la cubierta del libro en la venta de los ejemplares.

Con respecto al comercio exterior, conviene destacar en este mismo periodo y según datos del (FGEE) alcanzó los 557 millones de euros y un saldo positivo de 382 millones de euros en la balanza comercial. Destacan los siguientes datos:

- Se consolida América. México se mantiene como primer receptor, Argentina se recupera y Brasil es el que más progresa. Estados Unidos se afianza como uno de los mercados más importantes.

- El saldo neto de exportaciones crece casi el $22 \%$.

- Francia destaca como principal receptor en Europa de libros españoles.

Estos datos ofrecen un panorama interesante de la industria editorial española, situada entre las cinco primeras del mundo. Situados aquí, conviene precisar la importancia que tiene la cubierta cada vez que se edita un libro $y$, ante tal cantidad de libros publicados, qué importancia se da a la cubierta, el valor artístico y lo que significa para los lectores.

\section{El libro en sus cubiertas. Apunte histórico}

La estética del libro cambió radicalmente en España hacia 1896 con el modernismo, movimiento en el que destacaron el fotograbador Josep Thomas y los artistas A. de Riquer y
Adriá Gual (Trenc, 1977, p. 213). En aquel momento se produjo la ruptura con el mundo tradicional y la apertura a las corrientes europeas, de forma que la ilustración del libro pasó a ser decorativa en el interior y en las cubiertas.

Después del modernismo, la historia de la edición ha contado con grandes creativos desde que en el periodo de entreguerras las vanguardias escogieran las revistas y los libros como medio para la difusión masiva de sus trabajos. Si las publicaciones periódicas y los carteles fueron el medio para darse a conocer a finales del XIX y principios del XX, el libro fue el instrumento ideal para consignar y reafirmar el prestigio de los autores.

Por otra parte, los editores encontraron en la aportación de los ilustradores otra forma de competir en el mercado, ya que contar con la firma de los dibujantes significaba un punto de partida de alto nivel. Las grandes empresas como Calleja, Gustavo Gili, Calpe, Espasa, Zenit, Signo y tantas otras, contaron con artistas y diseñadores para las cubiertas, aunque la relación con los mismos no fue contractual, en sentido estricto, sino de colaboración.

En el diseño de cubiertas fue fundamental el uso de la tipografía, que los grandes impresores e ilustradores no solo dominaron sino que explotaron al máximo. Explica Trapiello que la vanguardia tipográfica española de los años treinta fue al mismo tiempo vanguardia política al aplicar los mismos criterios que los revolucionarios rusos, italianos y alemanes (Trapiello, 2006, p. 199). En muy pocos casos encontramos documentación sobre las cubiertas y su desarrollo, ni siquiera desde el aspecto económico. La conservación de documentos en las editoriales no ha sido la norma, y en el caso de las cubiertas se acentúa, al tratarse de material con un solo uso específico $y$, por tanto, no reutilizable en principio, salvo en los casos de facsímiles.

La pretensión del editor fue, por tanto, mostrar un trabajo nuevo, diferente a partir de las cubiertas, vinculando el sello a un determinado modelo de ilustración, en definitiva al creador. En el Diccionario de las Vanguardias, Juan Manuel Bonet (1995) recoge los nombres de los ilustradores que se dedicaron al libro en el periodo al que hemos hecho referencia, entre ellos Salvador Bartolozzi, Luis Bagaría o Rafael de Penagos. Pero hubo muchos más autores, entre ellos Manuel Benet, vinculado a Espasa, que supo combinar la tipografía con las imágenes sin utilizar el color, mientras que autores como Penagos recurrieron al clasicismo para impactar en el receptor. 
Después de la Guerra Civil hubo un largo periodo de transición que rompieron editoriales como Gustavo Gili con sus publicaciones de libros técnicos sobre arte (arquitectura, pintura, fotografía, etc.) o las dedicadas a la literatura como Seix Barral y Destino. Varias de estas editoriales recuperaron la fotografía para las cubiertas, sin dejar de utilizar la tipografía. En esa constante renovación se pretendió que la editorial fuera identificada por determinados modelos, y gran parte de ellas lo consiguieron, como Planeta con sus colecciones de Narrativa. Del trabajo de autor se pasó a la actividad en equipo a partir de la década de los ochenta del siglo XX, base de las actuales empresas dedicadas al diseño de cubiertas: Zac, Paso de Zebra, Mas Gráfica, El Golpe y tantas otras.

\section{Las colecciones como marketing editorial: Austral de Espasa y Libro de Bolsillo de Alianza}

Contar con una colección de renombre significa vender el producto con ventaja, porque los contenidos se insertan en modelos conocidos 0 reconocidos. Colección y editorial van así unidos, utilizando dos marcas, logos o títulos. El marketing editorial ha tenido y tiene su máximo exponente en el diseño de colecciones. Determinados títulos como Austral o Barco de Vapor, por poner dos ejemplos en periodos muy distantes, han sido bandera en sus respetivas editoriales (Espasa-Calpe y Santillana), hasta el extremo de convertirse en clásicos.

El nombre de Espasa-Calpe en América se divulgó a finales de los años treinta gracias a la creación de la colección Austral, cuyo diseño marcó toda una época y que se ha mantenido hasta la actualidad con retoques. Espasa realizó con esta colección una excepcional operación de marketing en los años setenta del siglo $\mathrm{XX}$, campañas que ha renovado hasta la actualidad. Andrés Trapiello señala que: "Pocos diseños editoriales han gozado de mayor popularidad que el de esta colección de bolsillo" (Trapiello, 2006, p. 262).

Otra de las grandes colecciones cuyas cubiertas sirvieron para el marketing editorial fue El Libro de Bolsillo, de la empresa Alianza. El responsable de las más de 1.500 cubiertas fue el diseñador Daniel Gil Pila (Santander, 1930-Madrid, 2004), quien estudió Artes y Oficios en Santander y Bellas Artes en Madrid antes de diseñar en 1951 su primera cubierta para el libro de Manuel Arce titulado Carta de paz a un hombre extranjero. En la década de los cincuenta estudió en la Escuela de UIm, dirigida por Otl Aicher, y al regresar a España se dedicó al diseño de discos. En 1966 comenzó a trabajar para Alianza y la colección que nos ocupa. Gil introdujo un nuevo lenguaje gráfico innovador y experimental, y su trabajo se convirtió en un referente para las nuevas generaciones de autores. En 1992 dejó Alianza tras 25 años de actividad y realizó logos para instituciones culturales, entre ellas el Museo Thyssen-Bornemisza. En 1984 le fue concedida la Medalla de Oro de Bellas Artes, y en el 2001 obtuvo una mención honorífica en los Premios Nacionales de Diseño, pero la rechazó.

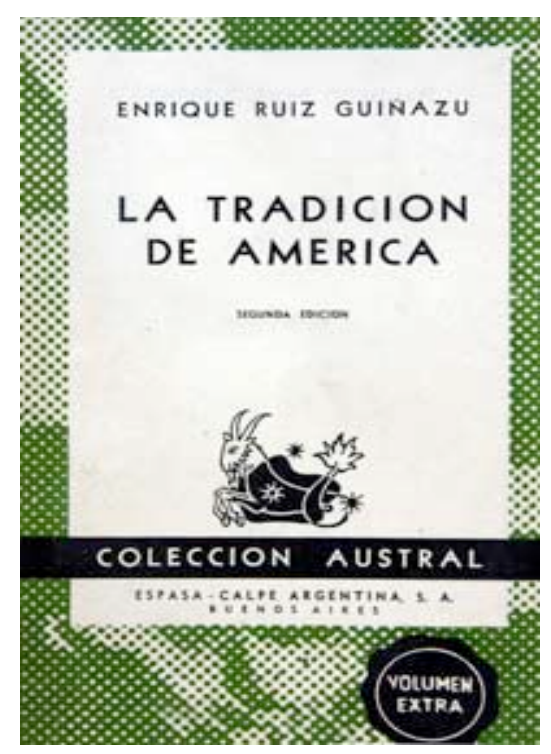

Figura 1. Portada de un volumen extra de la colección Austral de 1975.

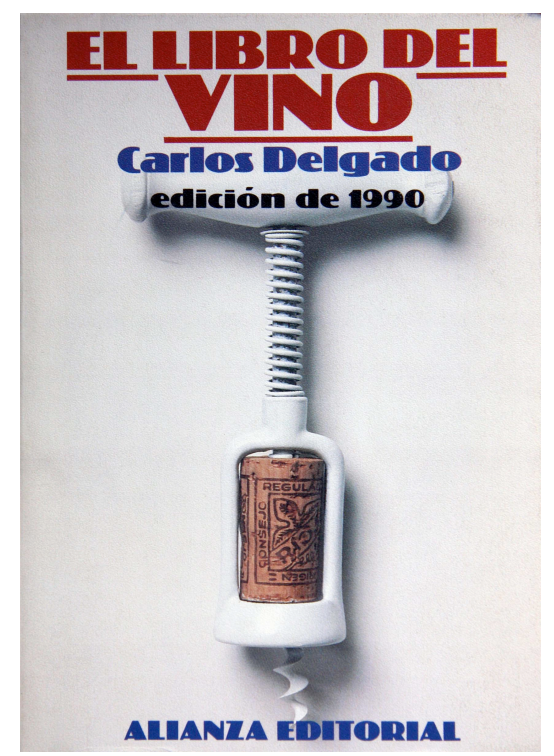

Figura 2. Portada de un Alianza Editorial en los años 90. 
4.1. La presencia del autor: el ejemplo de Risto Mejide

Risto Mejide, personaje televisivo en el programa Operación Triunfo (música), presentó en marzo de 2008 el libro titulado El pensamiento negativo: acierta mal y pensarás. Se trata de uno de los modelos de marketing editorial más significativos en los que la cubierta vende los contenidos desde el autor. El diseño, realizado por CalderonStudio, presenta sobre la fotografía de autor a página, realizada por Manuel Outumuro, sobre la que figuran los textos en tipografía cuidada, con dos formatos: menor para el título y mayor para el nombre y apellido del autor.

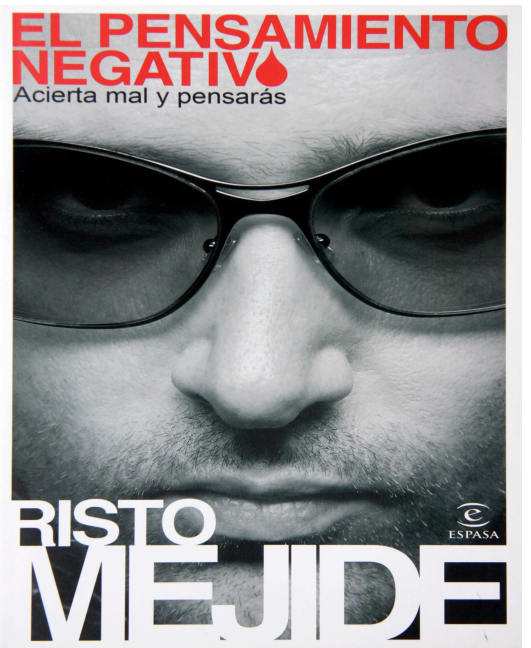

Figura 3. Portada de un libro en el que se cuida de forma especial la tipografía.

El diseñador corta la imagen del autor en primer plano, buscando la mirada que exhibe habitualmente en televisión tras gafas oscuras. Pretende por tanto casar el título con la imagen en la referencia al pensamiento. El resultado es impactante porque produce rechazo, generando un bucle que se invierte. Tal rechazo es el que hace que el marketing obtenga el éxito, porque el papel del tipo en televisión coincide con el diseño de la cubierta.

\section{Las cubiertas de los libros como mecanismo de marketing editorial}

El marketing editorial soporta una de las tareas fundamentales en la difusión del libro, entendiendo por difusión su comercialización. Los equipos de trabajo responsables de desarrollar los proyectos son especialmente creativos en todos sus movimientos, ya que de sus resultados dependerá el éxito de la operación.

\subsection{El departamento de marketing}

El departamento responsable de la elaboración de las cubiertas es el de marketing, cuyas funciones se concretan en una editorial en los siguientes campos:

1. Publicidad: difusión del libro (campañas publicitarias en los medios)

2. Promoción: información sobre el libro (catálogos, folders, folletos, etc.)

3. Diseño: realización del libro (preparación de cubiertas)

4. Control del producto: reimpresiones (tiradas de ejemplares)

El marketing editorial es uno de los factores esenciales en el proceso de elaboración del libro. El desconocimiento de las tareas que se llevan a cabo en los departamentos responsables del marketing es casi absoluto y convendría mejorar este aspecto para dar otra presentación a los libros.

\subsection{2. Diseño de cubiertas}

El diseño de una cubierta responde a varios criterios, y no siempre relacionados con los contenidos. Se presentan así varios casos en función del autor, el contenido específico, la materia general tratada, y la conjunción de los anteriores. Para llevar a cabo el diseño se consideran varios aspectos: el autor, el título y los contenidos. Si bien se trabaja con los índices y con los contenidos de la cubierta: la selección especial de imágenes y el juego de la tipografía de los textos.

\subsection{Las cubiertas como marketing editorial}

Vender desde las cubiertas puede parecer fácil, pero no lo es. En ocasiones resulta casi imposible entender la idea del autor y plasmarla de manera gráfica. Hay libros que por su temática, por ejemplo matemáticas, pueden ser ilustrados con números o elementos que representen alguna de las especialidades de esa materia. Otros libros permiten más creatividad; por ejemplo, las novelas, donde el autor ha de volcar una parte de lo que quiere el autor, al menos.

Una de las cuestiones en la elección de la cubierta es no permitir que el autor tome parte en ello, tampoco el editor, ni los elementos ajenos al tema. Esto se debe a que limitan la creatividad del diseñador puesto que le dan pautas o pistas que el diseñador quizás no quiera considerar y en ese caso se ve obligado a ceder parte de sus ideas en función de lo que le han comentado los autores. 


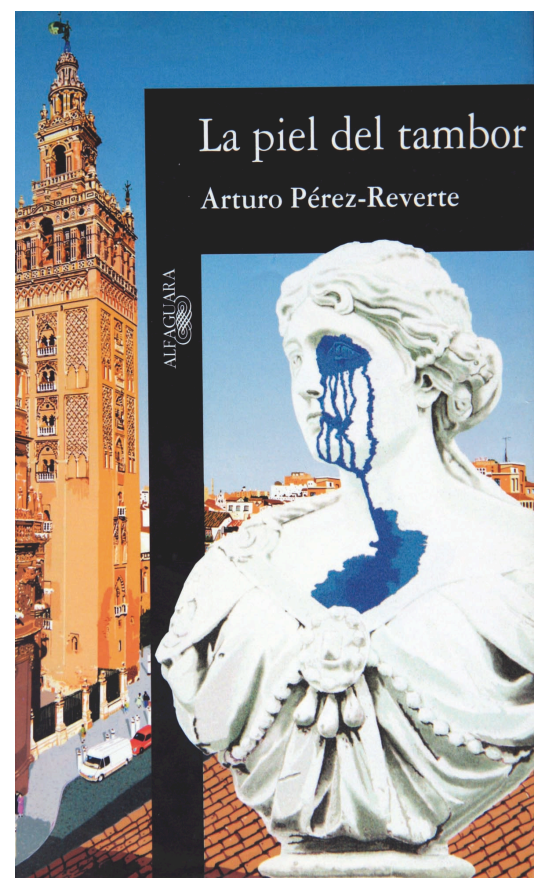

Figura 4. Portada de una de las novelas de Arturo Pérez Reverte.

\section{Derechos de autor de las imágenes usadas como cubiertas de los libros}

El primer contacto visual del posible lector con el libro lo es su forma, su color, su volumen, pero más que eso lo es su cubierta. No son pocas las veces en que un usuario de una biblioteca al referirse a un libro no lo hace a partir de su autor o título, sino por su tamaño, y más aún, por su cubierta. Los editores y diseñadores gráficos conocen bien esta situación y encuentran en ella un medio para crear vínculos entre la obra y el lector. Por tanto se pone especial énfasis en la ilustración, tanto de los contenidos como para la cubierta. Estos dos elementos son por sí solos una obra de carácter intelectual que se combinan de manera armoniosa con el texto y así van conformando una obra literaria.

Desde la perspectiva del derecho de autor las cubiertas son obras "por encargo" Esto es, el productor de un libro se dará a la tarea de solicitar a un diseñador la composición de una imagen que eventualmente pueda representar la idea general del contenido del libro. Otras veces esas imágenes encargadas no tienen mucho que ver con el contenido, pero en ambas situaciones el resultado del trabajo gráfico se convertirá en la "carta de presentación" del libro. Esta posición legal es muy favorable al editor, pues se asume que el diseñador al recibir un pago por su trabajo automáticamente cede a favor del editor todos sus derechos patrimoniales, es decir, sus derechos de reproducción de la imagen, de comunicación, de distribución y hasta de transmisión electrónica. En otras palabras, el diseñador no se podrá oponer a que el editor reproduzca la imagen en tantas ocasiones como el tiraje lo marque, así como tampoco se podrá oponer a que la imagen sea utilizada en cualquier tipo de promocionales del libro, ya sean estos pendones, separadores, espectaculares o cualquier otro medio de difusión que el editor considere oportuno.

Habrá legislaciones nacionales en materia de derecho de autor que no consideren la transmisión de los derechos patrimoniales de las obras por encargo de manera tácita y requieran la celebración de un contrato. Si este fuera el caso, el editor debe prever todos los escenarios posibles en los que requeriría hacer uso de la imagen, como lo pudiera ser en ulteriores ediciones de la obra. Ya sea una transmisión tácita o expresa de derechos patrimoniales, el editor debe asegurarse que la imagen que recibe es original de quien la hace y que, de no ser así, el responsable de cualquier perjuicio lo será el diseñador y no el editor.

Existe una segunda opción desde el derecho de autor que puede dar origen a la cubierta: cuando la imagen a usarse tiene existencia previa y ajena al libro, pudiendo ser esta una fotografía o una pintura que alguno de los creadores del libro encuentran factible como medio para promoverlo. Cualquiera que fuera la situación es obligación del editor adquirir todos los derechos patrimoniales necesarios sobre la imagen pues no solo se reproducirá en la cubierta, sino que tendrá que modificarse al colocar sobre ella los datos del libro. Por tanto, al igual que en los contratos de cesión de derechos celebrados con los diseñadores gráficos, se deberán prever todos los usos; y, a la vez, evitar responsabilidades al editor por falta de originalidad de la imagen o por ser ofensiva de derechos de terceros. Esto es, cuando se usan fotografías de personas, de lugares privados o de objetos peculiares.

\subsection{El uso de imágenes en las cubiertas}

La consecuencia para el editor de obtener legalmente el permiso de uso de las imágenes como cubiertas le permite ir adquiriendo una serie de derechos conexos sobre la obra y por tiempo determinado; a veces dos años, a veces hasta cincuenta años, todo depende de la legislación aplicable. Así por ejemplo, la presentación, la cubierta, los tipos de letra, las viñetas, orlas, florones y demás elementos gráficos que puedan ser identificados como originales y propios 
del editor, le permitirán ir conformando la diagramación de la obra y exigir sobre estas características el respeto de las mismas, inclusive cuando el texto de la obra se encuentre en el dominio público. En la práctica estos derechos se ven ejercidos contra obras facsimilares ilegales, tanto impresas como digitales.

Ahora bien, el uso de la tecnología -como en no pocas ocasiones- causa ciertas interrogantes respecto al uso de las cubiertas. ¿EI vendedor de libros que se anuncia en la Internet tiene derecho a digitalizar la cubierta de un libro para promover su venta? ¿La biblioteca que cuenta con un catálogo en línea puede digitalizar la cubierta para indicar la existencia del libro dentro de sus colecciones? En ambos casos se habla de la digitalización, entendida ésta como una reproducción y, en consecuencia, de uno de los derechos del editor; sin embargo, el fin comercial que persigue el vendedor de libros beneficia de manera directa al editor $y$, por tanto, no se considera violatoria. No obstante, esta afirmación no puede traducirse como contundente, pues dentro de las excepciones y limitaciones a los derechos patrimoniales identificadas en diferentes legislaciones en materia de derechos de autor no se encuentra definido ese permiso.

Para el caso de las bibliotecas que deseen digitalizar la cubierta, tampoco existe un artículo o principio que lo permita; por lo que, al igual que en todos los casos del derecho de autor, se deberán atender las peculiaridades del caso y no las generalidades. Esto es, no estará de más preguntar a los editores si es que encuentran objeción alguna en que sus cubiertas sean digitalizadas para promover la lectura de sus obras, aunque tampoco vendría mal que los editores desde la página legal de sus libros indicaran con detalle el permiso o prohibición de realizar cualquiera de estos actos.

\subsection{Leyes que afectan la industria editorial}

Al igual que en toda industria, en la editorial existe un marco legal que regula todas sus actividades. Ya sean éstas la compra de materiales, la contratación de personal o la venta y distribución de sus productos terminados, siempre prevalece una reglamentación que supervisa que éstas actividades sean lo más equitativas posible para los involucrados.

De entre esta reglamentación en España, destaca la Ley 10/2007, de 22 de junio, de la lectura, del libro y de las bibliotecas. Ésta es producto de un acalorado debate entre todos los involucrados, representado por la inclusión de 130 enmiendas que modifican al texto original.
Entre los puntos de mayor relevancia, se encuentra el establecimiento de un canon que obliga a todas las bibliotecas del territorio a pagar la cantidad de 0,20 euros por libro prestado. En ningún momento podría decirse que ésta ha sido una decisión fácil o que no haya sido cuestionada en numerosas ocasiones por bibliotecarios y lectores, pero es producto de un análisis en el que se cuestionó desde la perspectiva del derecho de autor si es que la actividad de préstamo en una biblioteca debería o no generar un beneficio a los titulares de esos derechos. La solución que se le encontró a esta propuesta fue que las administraciones públicas se encargaran de liquidar estas cuotas y evitar así perjudicar la actividad lectora.

Otra característica de esta ley es la inserción del establecimiento de un precio fijo de los libros, que con excepción de los materiales reservados para la educación obligatoria, indica un estándar de costos de venta. Al igual que la del canon bibliotecario, esta inserción tampoco ha sido un tema fácil, pero también se ha visto como siempre una organización eficiente por parte de la industria editorial, la cual, a través de sus representantes, expone y debate con los bibliotecarios y los lectores cuál pudiera ser el mejor escenario para todos.

Ambas inserciones aún son novedosas y, poco a poco, se verá en la práctica cómo afectan o benefician tanto a la industria como a los servicios bibliotecarios y, por supuesto, a la lectura. Por tanto, queda pendiente el seguimiento que deba hacerse a estas leyes y su aplicación a la vida diaria, a fin de comprobar si es que son eficientes o deberán modificarse.

\section{Referencias}

Bonet, Juan Manuel (1995). Diccionario de las vanguardias. Madrid: Alianza, 1995

ICEX. El español es la lengua extranjera con mayor demanda en las bibliotecas públicas de Estados Unidos. http://www.oficinascomerciales.es/icex/ (14 de mayo de 2008)

Federación de Gremio de Editores de España. Comercio interior del libro en el año 2006. http://www.federacion editores.org/0_Resources/Documentos/Informe_Sector_ editorial2006.pdf (1-07-2008)

Federación de Gremio de Editores de España. Comercio interior del libro en el año 2005. http://www.federacion editores.org/0_Resources/Documentos/SECTOR_EDIT_ ESPANOL_2005.pdf (1-07-2008)

Pérez Bazo, Javier (ed.) (1998). La vanguardia en España París: Cric \& Ophrys, 1998.

Trapiello, Andrés (2006). Imprenta moderna. Tipografía y literatura en España, 1874-2005. Valencia: Campgràfic 2006.

Trenc, Eliseo (1977). Las artes gráficas en la época modernista en Barcelona. Barcelona: Gremio de Industrias Gráficas, 1977. 